\title{
Kernos
}

Revue internationale et pluridisciplinaire de religion grecque antique

$14 \mid 2001$

Varia

\section{Fr. FRONTISI-DUCROUX, Dédale}

\section{Vinciane Pirenne-Delforge}

\section{(2) OpenEdition}

\section{Journals}

Édition électronique

URL : http://journals.openedition.org/kernos/789

DOI : $10.4000 /$ kernos.789

ISSN : 2034-7871

Éditeur

Centre international d'étude de la religion grecque antique

Édition imprimée

Date de publication : 1 janvier 2001

Pagination : 316-317

ISSN : 0776-3824

Référence électronique

Vinciane Pirenne-Delforge, «Fr. FrontisI-Ducroux, Dédale», Kernos [En ligne], 14 | 2001, mis en ligne le 14 avril 2011, consulté le 21 septembre 2020. URL : http://journals.openedition.org/kernos/789 ; DOI : https://doi.org/10.4000/kernos.789 
tions, $\mathrm{Cl}$. Calame aborde son premier chapitre par une réflexion sur la notion de mythe, montrant que mutbos, à l'époque archaïque et classique, ne désigne pas une classe de récits traditionnels auxquels on dénierait toute valeur de vérité. Le muthos ne s'oppose pas ici à un quelconque logos. S'il arrive que des philosophes critiquent des mythes, c'est en raison de la fonction éducative que ces récits poétiques exercent dans la cité et que parfois, à leurs yeux, ils assument dans un sens qui ne convient pas. Les mythes grecs n'ont d'existence que dans des compositions poétiques qui les portent à leur public. On doit regretter, d'autre part, que l'anthropologie ait accrédité la notion de mythe comme mode particulier de la pensée humaine, - une réalité transcendentale en quelque sorte -, la délestant ainsi de son aspect narratif et appauvrissant du même coup la richesse sémantique de ces formes de discours toujours liés à des manifestations particulières de la vie sociale et culturelle. Une impressionnante revue des interprétations qu'a connues, depuis l'Antiquité jusqu'à nos jours, le mythe de Déméter et de Corè, révèle une tendance commune à faire des mythes des universaux, en même temps qu'elle conduit à relativiser ces essais successifs de naturalisation et d'ontologisation de catégories interprétatives. En réalité, " chaque mythe ne peut être lu que dans la version particulière qui le porte à son destinataire ". C'est ce que l'A. va tenter de faire un peu plus loin à propos du rapt de Perséphone tel que le raconte l'Hymne bomérique : cette trame narrative doit être comprise dans le complexe d'effets de sens qu'elle suscite et dans l'accomplissement du rituel que le récit est censé instituer. Auparavant, il aura montré, en scrutant les dits de plusieurs penseurs grecs, que les Anciens ont toujours été sensibles à la valeur pragmatique des récits fictionnels.

Ces trop brèves esquisses auront fait, je l'espère, pressentir les mérites de cet ouvrage dont il faut souhaiter qu'il suscite un large débat.

André Motte (Université de Liège)

Frontisi-Ducroux Françoise, Dédale. Mythologie de l'artisan en Grèce ancienne. Préface de Pierre Vidal-Naquet. Posface inédite de l'auteur, Paris, La Découverte/Poche, 2000. 1 vol. $12,5 \times 19 \mathrm{~cm}, 241$ p. (Sciences bumaines et sociales). ISBN : 2-7071-3311-6.

Ce petit ouvrage est la réimpression anastatique de la thèse de l'A. initialement publiée en 1975, à laquelle est ajoutée une postface intitulée Dédale, an 2000. Des daidala à la figure de Dédale, c'est tout le champ de la mètis artisanale qu'explore cet ouvrage, que rien n'est vraiment venu remplacer depuis sa publication, pas même le Daidalos de Sarah Morris (Princeton, 1992) conçu dans une perspective toute différente. On saura gré à l'A. de mettre clairement en évidence ce qu'elle n'aurait pas refait à l'identique, s'il avait fallu réécrire ce livre, et le pourquoi de ces « repentirs ». Il s'agit essentiellement des développements qui concernent les relations entre le mythe de Dédale, les débuts de la sculpture grecque et la technologie du bronze, en somme tout ce qui pose le problème « du rapport de la création mythique avec les réalités techniques » (p. 220). Les représentations grecques de l'origine de la sculpture relèvent de la construction intellectuelle plus que de l'histoire de l'art proprement dite. Elles relèvent autant du mythe que le personnage de Dédale lui-même. Mais il est impossible de s'en tenir à ce seul constat. Et l'A. d'affirmer quelques pages plus loin : « Le problème demeure cependant du rapport des constructions de l'imaginaire avec la réalité. Il s'agit de savoir ce qui dans le réel a été effectivement sélectionné, ce qui a stimulé la création mythique, poétique ou figurative », tous ces « objets bons à penser » chers à Lévi-Strauss (p. 224). La postface ouvre donc de nouvelles 
perspectives, sorties en droite ligne des travaux de ce que l'on appelle un peu paresseusement «l'École de Paris ». C'est sans doute pourquoi l'A. ne prend pas la peine de rencontrer - ni même de mentionner - le gros compte rendu critique qui lui avait été adressé dans Gnomon (51 [1979], p. 42-48) où c'étaient les principes même de l'analyse qui étaient mis en cause, avec une sévérité excessive. Signalons pour terminer que l'index est lui aussi réimprimé à l'identique et qu'il n'intègre donc pas les apports de la postface.

Vinciane Pirenne-Delforge (FNRS - Université de Liège)

Michel Fauquier, Jean-Luc Villette, La vie religieuse dans les cités grecques aux $V^{e}$, ve et $I^{r e}$ siècles, Paris, Ophrys, 2000. 1 vol. $15 \times 21 \mathrm{~cm}$, 448 p. (Coll. Syntbèse $\Sigma$ Histoire). ISBN : 2-7080-0967-2.

Rédigé par deux professeurs de Lycée et dédié à leurs étudiants de la promotion 1999/2000, cet ouvrage, bien que cela ne soit jamais dit, semble donc destiné à un public étudiant ou, au moins, émaner d'un cours dispensé à des étudiants. Il s'organise en trois parties dont la première, qui couvre les trois quarts de l'ensemble avec ses seize chapitres, s'intitule « Le point sur le sujet ». La deuxième partie se veut une «Initiation à la recherche » et compte trois chapitres reprenant l'alphabet et les unités de mesure grecs, un très bref aperçu des sources de nos connaissances et un coup d'œil encore plus rapide sur les « Approches de la vie religieuse en Grèce antique " où seule la recherche en France est représentée - avec un écho, notamment, à la dernière question de l'agrégation sur le thème de la guerre... La troisième partie intitulée « Dossiers » rassemble une série de cartes et de plans de sanctuaires et de sites, très utiles pour des étudiants, un dossier sur «Diverses approches de Zeus» sans doute beaucoup moins utile, et un dernier dossier sur le «sanctuaire» qu'est l'île de Délos. Le livre se referme sur des « Repères chronologiques », un glossaire et une bibliographie thématique,

Il s'agit donc d'un fort ouvrage où pas moins de 331 pages sont consacrées à la religion grecque de la période classique. Les $A$. s'en défendent sous prétexte qu'on ne peut parler ni de « religion grecque » ni de «période classique ». D'où le titre choisi. Soit. Tout en étant conscients des limites de notre vocabulaire et des dangers d'anachronisme qu'il recèle, il faut bien utiliser des mots. Et il y a quelque paradoxe à refuser le mot «religion » tout en utilisant abondamment l'adjectif "religieux » (Introduction, p. 11-15). Les subdivisions de la première partie font se succéder "La sphère religieuse " (La dimension spirituelle de la sphère religieuse - La dimension matérielle de la spbère religieuse - Le monde divin et les Enfers), puis "Le culte et ses desservants " (Le personnel religieux; Le sacrifice; Les rites d'accompagnement du sacrifice), ensuite " La vie religieuse dans le cadre civique »(Des cadres marqués par le religieux - Le citoyen, au cour du système religieux - Les autres habitants, à la marge), ensuite "La vie religieuse dans le cadre panhellénique " (La dimension religieuse de la guerreLes Jeux panbelléniques - Les grands sanctuaires oraculaires), et enfin « Aux marges des pratiques religieuses civiques (Le mystérisme - Le dionysisme - Les cultes privés - Des cultes et des pratiques déviants), le tout couronné d'une brève conclusion.

J'ai refermé cet ouvrage avec un sentiment de malaise. J'ignore à qui, finalement, le livre s'adresse, et là réside sans doute la source du malaise. La projet de vulgarisation est manifeste, mais la volonté de faire écho à des débats de spécialistes rend souvent le propos confus. Et s'il s'agissait de produire un manuel pour des étudiants spécialisés, il aurait fallu élargir considérablement les débats et ne pas les limiter aux travaux francophones, quelles qu'en soient les 